\title{
Genetic structure of whiting Merlangius merlangus in the northeast Atlantic and adjacent waters
}

\author{
Grégory Charrier ${ }^{1,2, *}$, Steve H. Coombs ${ }^{3}$, Ian H. McQuinn ${ }^{4}$, Jean Laroche ${ }^{1}$ \\ ${ }^{1}$ Laboratoire LEMAR (UMR CNRS 6539), Institut Universitaire Européen de la Mer, Place Nicolas Copernic, \\ Technopôle Brest-Iroise, 29280 Plouzane, France \\ ${ }^{2}$ NOAA Southwest Fisheries Science Center, Santa Cruz Laboratory, 110 Shaffer Road, Santa Cruz, California 95060, USA \\ ${ }^{3}$ The Marine Biological Association of the United Kingdom, The Laboratory, Citadel Hill, Plymouth PL1 2PB, UK \\ ${ }^{4}$ Hydroacoustic Laboratory, Marine Fish and Marine Mammals Division, Department of Fisheries and Oceans, \\ Maurice Lamontagne Institute, CP 1000, 850 route de la Mer, Mont-Joli, Quebec, Canada
}

\begin{abstract}
Accurate identification of stock boundaries is essential for efficient fisheries management; hence, the present study focused on the genetic structure of whiting. To this aim, 488 individuals collected from the southern Bay of Biscay to the southern Norwegian coast were genotyped using 7 microsatellites. A low level of genetic structuring was detected in Atlantic waters; only the Bay of Biscay differentiated from more northern samples. The lack of genetic structure along the western margin of the British Isles is consistent with a high level of passive transport of pelagic eggs and larvae due to the combined influence of the North Atlantic Current and the Shelf Edge Current. High levels of dispersal could also occur between the western British Isles and the North Sea through both the branching of the North Atlantic Current into the northern North Sea and the residual current flowing from the English Channel to the Southern Bight. In contrast, a significant genetic structure was identified within the North Sea, and this may be associated with the complex oceanography of this basin and retention systems reducing larval dispersal. In addition, considering also genetic, phenotypic and tag-recapture data collected on whiting, a learned homing behaviour of adults toward spawning areas may be hypothesised.
\end{abstract}

KEY WORDS: Whiting $\cdot$ Merlangius merlangus $\cdot$ Microsatellites $\cdot$ Genetic structure $\cdot$ Larval dispersal Resale or republication not permitted without written consent of the publisher

\section{INTRODUCTION}

As the marine environment is generally highly dispersive, marine species are often supposed to be poorly structured. In addition to a potentially extensive gene flow, other features of marine fish, such as large population sizes and a recent origin of populations since the Last Glacial Maximum ( 15000 yr ago), tend towards generally low levels of genetic structuring. In this context, the choice of appropriate genetic markers is a crucial step in determining the patterns of population differentiation. Among the markers used over the last decade, microsatellites have been among the most promising tools to investigate population genetics in weakly structured species, such as marine fish. The numerous studies conducted on cod Gadus morhua are good illustrations of the higher efficiency of these hypervariable loci in identifying population units in marine fish (Ruzzante et al. 2000, Hutchinson et al. 2001) compared to other markers such as allozymes (Child 1988, Pogson et al. 1995) or mitochondrial DNA (Carr et al. 1995).

In the present study, microsatellites were chosen to investigate the genetic structure of whiting Merlangius merlangus in the northeast Atlantic and adjacent waters. This gadoid fish is encountered from Portugal to Iceland and northern Norway and is represented by the sub-species $M$. merlangius euxinus in the northeast Mediterranean and Black Sea (Quéro \& Vayne 1997). Whiting is highly targeted by fishermen in northern European fisheries, and the stock's health seems either uncertain or outside safe biological limits 
(ICES 2004). Thus, further research would help to improve management of this species in particular by more accurate identification of stock boundaries through increased knowledge of population structure.

Whiting displays a longer pelagic life than other gadoids: after a larval pelagic phase common to all Gadidae, young individuals $>12 \mathrm{~mm}$ long live in commensalism with jellyfishes (Cyanea sp. or Chrysaora sp.) and finally move to the seabed when they reach a length of 5 to $10 \mathrm{~cm}$ to assume a demersal life (Quéro \& Vayne 1997). As a consequence, whiting is characterised by a wide dispersion potential for the young stages from spawning areas. Moreover, the spawning period of females extends over $10 \mathrm{wk}$ at least (Quéro \& Vayne 1997), thus providing a high potential for gene flow between spawning units with possible migrations of mature females between distinct spawning grounds during their long period of sexual maturity. All these biological traits may potentially prevent genetic differentiation of whiting populations by ensuring considerable gene flow over large areas.

However, substantial population structure has been suggested around the British Isles from the results of several approaches, including meristic trait analysis (Gamble 1959), parasitic infestation studies (Kabata 1967, Hislop \& MacKenzie 1976, Pilcher et al. 1989), tag-recapture data (Williams \& Prime 1966, Hislop \& MacKenzie 1976) and genetic surveys (Child 1988, Galvin et al. 1995, Rico et al. 1997). In particular, these studies have together underlined some population structure within the North Sea, and have led to the hypothesis that the Dogger Bank may represent a regional boundary between northern and southern populations in this area (Kabata 1967, Hislop \& MacKenzie 1976, Pilcher et al. 1989, Rico et al. 1997). Nevertheless, contrary to the other approaches, genetic investigations have not yet led to a conclusive view of population structure in whiting.

The present study focused on the genetic structure of whiting from the southern Bay of Biscay to the Norwegian coast, based on microsatellite data. Our aims were (1) to provide additional genetic data concerning population structure of whiting in European waters and notably to confirm the structure previously observed in the North Sea from other methods; (2) to identify factors, either hydrodynamical or biological/ ecological, related to the contemporary genetic structure of whiting.

\section{MATERIALS AND METHODS}

Sampling. A total of 488 individuals of Merlangius merlangus were sampled from 10 locations (between 45 and 57 ind. per site) (Table 1, Fig. 1). In order to reduce the potential risk of sampling mixed population units, we targeted only mature adults (total length $>25 \mathrm{~cm}$ ) during the spawning period (between February and April), when fish are gathered near or on the spawning grounds, with the exception of the Dingle sample (southwest Ireland), which was composed of juveniles (14 to $20 \mathrm{~cm}$ in length). Fin samples were collected immediately after landing or directly on board and were stored in $95 \%$ ethanol.

Microsatellite amplification and screening. DNA samples were extracted using a classical phenolchloroform method. DNA was resuspended in a volume of 100 to $250 \mu \mathrm{l}$ of TE $10 \times$ buffer and stored at $-20^{\circ} \mathrm{C}$.

First, 37 microsatellite loci isolated from other species were tested on whiting: 20 of Theragra chalcogramma (O'Reilly et al. 2000), 4 of Micromesistius poutassou (Moran et al. 1999), 4 of Melanogrammus aeglefinus (Lage \& Kornfield 1999), 4 of Gadus morhua (Brooker et al. 1994) and 5 of Pollachius pollachius (Charrier et al. unpubl. data). These loci were selected because of the positive results obtained during cross-species amplifications (Brooker et al. 1994, O'Reilly et al. 2000, Ryan et al. 2005). Loci amplifications via the polymerase chain reaction (PCR) were performed on 5 individuals in $10 \mu \mathrm{l}$ volumes containing $1 \mu \mathrm{l}$ of DNA, $1 \times$ reaction buffer (Uptima), $0.074 \mathrm{mM}$ dNTPs mix, $0.2 \mu \mathrm{M}$ primers $\mathrm{F}$ and $\mathrm{R}$, $0.25 \mathrm{U}$ Taq Uptitherm DNA polymerase (Uptima) and between 1.5 and $2.5 \mathrm{mM} \mathrm{MgCl}_{2}$, depending upon the locus tested. PCR amplifications were performed in a Geneamp PCR System 9700 (Perkin Elmer). In order to increase the stringency of microsatellite amplification, a touchdown procedure, adapted from O'Reilly et al. (2000), was incorporated in the thermal cycling regime of $\left(94^{\circ} \mathrm{C}\right.$ for $3 \mathrm{~min}, \mathrm{Tm}+4^{\circ} \mathrm{C}$ for $2 \min , 72^{\circ} \mathrm{C}$ for $1 \mathrm{~min}) \times 1 ;\left(94^{\circ} \mathrm{C}\right.$ for $30 \mathrm{~s}, \mathrm{Tm}+3^{\circ} \mathrm{C}$ for $30 \mathrm{~s}\left[-1^{\circ} \mathrm{C}\right.$ per cycle], $72^{\circ} \mathrm{C}$ for $\left.1 \mathrm{~min}\right) \times 13$; and $\left(94^{\circ} \mathrm{C}\right.$ for $30 \mathrm{~s}$, $\mathrm{Tm}-9^{\circ} \mathrm{C}$ for $30 \mathrm{~s}, 72^{\circ} \mathrm{C}$ for $\left.1 \mathrm{~min}\right) \times 26 ;\left(72^{\circ} \mathrm{C}\right.$ for $5 \min ) \times 1$.

Table 1. Merlangius merlangus. Sampling details

\begin{tabular}{|llcc|}
\hline $\begin{array}{l}\text { Collection } \\
\text { site }\end{array}$ & $\begin{array}{l}\text { Sampling } \\
\text { date (2002) }\end{array}$ & Code & $\begin{array}{c}\text { Sample } \\
\text { size }\end{array}$ \\
\hline Cape Breton & 8 Mar & $\mathrm{Cb}$ & 46 \\
Bay of Audierne & 8 Feb & $\mathrm{Au}$ & 48 \\
Celtic Sea & 10 Apr & $\mathrm{Cs}$ & 57 \\
Dingle & 20 Apr & $\mathrm{Di}$ & 50 \\
Irish Sea & 12/13 Mar & $\mathrm{Ir}$ & 50 \\
Western Hebrides & Mar & $\mathrm{Wh}$ & 46 \\
Southern Bight & 20 Feb & $\mathrm{Sb}$ & 48 \\
Flamborough Head & 18 Feb & $\mathrm{Fh}$ & 48 \\
Dogger Bank & 12 Feb & $\mathrm{Db}$ & 45 \\
Skarvöyni & Feb/Mar & $\mathrm{Sk}$ & 50 \\
\hline
\end{tabular}


PCR products were analysed on $1.5 \%$ agarose gel stained with ethidium bromide. Electrophoresis was performed at $130 \mathrm{~V}$ for approximately $30 \mathrm{~min}$ in $0.5 \%$ TBE buffer and then visualised with UV light. Only loci with clearly defined bands were retained for the subsequent step, which consisted in testing the range of polymorphism of each locus. Between 5 and 10 individuals were tested for each of the selected loci. PCR amplifications were carried out following the protocol mentioned above, except for the addition of $0.05 \mu \mathrm{M}$ forward primer end-labelled with IRDye 800 (Li-Cor) and $0.4 \mu \mathrm{M}$ reverse primer. The amplification profile included a touchdown procedure, as described above, and was composed of a total of 20 to 30 cycles according to the individual locus. Loading buffer ( $5 \mu \mathrm{l})$ was added to the PCR products and $1 \mu \mathrm{l}$ was loaded on $8 \%$ denaturing polyacrylamide gels of $25 \mathrm{~cm}$ with $1 \%$ TBE buffer. Gels were run on an automated sequencer IR2 (Li-Cor) using Eseq software (Li-Cor) during 1 to $3 \mathrm{~h}$ at $1500 \mathrm{~V}$ and $50^{\circ} \mathrm{C}$. Gels were then analysed with Gene Profiler (Scan Analytics).

Finally, 7 polymorphic loci were retained for this study: 3 of Theragra chalcogramma (Tch8, Tch10 and Tch20) (O'Reilly et al. 2000), 1 of Micromesistius poutassou (MpouBW13) (Moran et al. 1999), 1 of Gadus morhua (Gmo02) (Brooker et al. 1994) and 2 of Pollachius pollachius (Pop14c \& Pop18a; Table 2) (Charrier et al. unpubl. data). For each locus, between 10 and $30 \%$ of the individuals were genotyped 2 to 3 times to limit allele scoring errors.

Data analysis. Allelic diversity and observed and unbiased expected heterozygosities were computed for each location with POP100GENE v.1.1.02 (Piry \& Bouget 1999). Departure from Hardy-Weinberg equilibrium (heterozygote deficiency or excess) was calculated for each locus and each location with GENEPOP v.3.4 (Raymond \& Rousset 1995) according to Weir \& Cockerham's $f$ and was tested using the Markov chain method (10000 dememorisation steps, 1000 batches, 5000 iterations) to obtain unbiased estimates of the exact $p$-value. Linkage disequilibrium was tested using the Markov chain method (10000 dememorisation steps, 1000 batches, 5000 iterations) and Fisher's exact test.

The genetic differentiation was assessed using $F_{\mathrm{ST}}$ and exact tests of population differentiation (Raymond $\&$ Rousset 1995). Global and pairwise $F_{\mathrm{ST}}$ were estimated using Weir \& Cockerham's $\theta$ with GENETIX v.4.05 (Belkhir et al. 2004). The significance of $\theta$ was tested using 10000 permutations. Global and pairwise exact tests of genic differentiation were calculated using GENEPOP v.3.4. Allelic frequencies were compared using a Markov chain method (10000 dememorisation steps, 1000 batches, 5000 iterations) and Fisher's exact test under the null hypothesis (allelic dis-

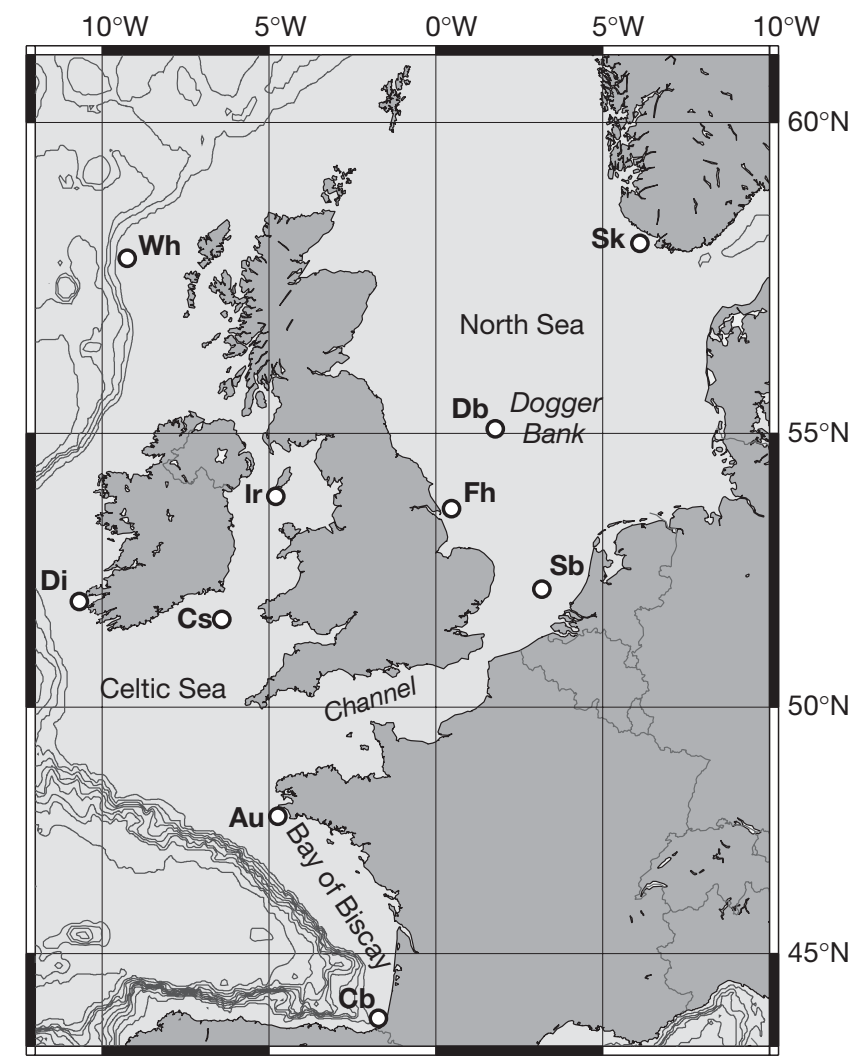

Fig. 1. Merlangius merlangus. Sampling locations of whiting. Site codes, see Table 1

tribution is identical among samples). This approach differs from $F_{\mathrm{ST}}$ estimation in the fact that exact tests of genetic differentiation are not based on any mutational model and give more weight to rare alleles than Wright's $F_{\mathrm{ST}}$. Sequential Bonferroni correction (Rice 1989) for multiple comparisons was applied for each set of independent tests performed simultaneously.

Table 2. Pollachius pollachius. Primers and temperature for each of the 2 microsatellites developed in pollack (Charrier et al. unpubl. data) and used in the present study

\begin{tabular}{|lc|}
\hline Primers & $\begin{array}{c}\text { Temp. } \\
\left({ }^{\circ} \mathrm{C}\right)\end{array}$ \\
\hline Pop14c & 60 \\
Pop14cF & \\
5' ACA CAC ACA CAA AAT ACG ATT CCT 3' \\
Pop14cR \\
5' TGA CGA TGA GGA GGG GGA TG 3' \\
Pop18a \\
Pop18aF \\
5' ATT TTT GTC TGT CTG CCT GGC 3' \\
Pop18aR \\
5' TCT CTA CTT TGC TCA GTC AGG 3' \\
\hline
\end{tabular}


In addition, a principal component analysis (PCA) of genetic data was performed with PCA-GEN v.1.2 (Goudet 1999) to examine the relationships among populations. The vectorial representation of the PCA was then obtained using STATISTICA v.6.1 (Statsoft). By synthesising the genetic data with minimum loss of information, such a factorial method allows a graphical visualisation of the relationships between samples in a more comprehensive way than pairwise comparison matrices.
Finally, correlation between pairwise geographical distances and pairwise linearised $F_{\mathrm{ST}}\left(F_{\mathrm{ST}} /\left(1-F_{\mathrm{ST}}\right)\right)$ was tested using Mantel test as implemented in GENETIX v.4.05 (10000 permutations). This analysis allowed investigation of the hypothesis of isolation by distance among populations in European waters. Distances were measured as the minimum geographical distances on the continental shelf (0 to $200 \mathrm{~m}$ depth) between sampling locations. It is however recognised that adjacency between populations may be more

Table 3. Merlangius merlangus. Number of alleles $\left(N_{\mathrm{A}}\right)$, observed $\left(H_{\mathrm{obs}}\right)$ and unbiased expected $\left(H_{\mathrm{exp}}\right)$ heterozygosities and $F_{\mathrm{IS}}$ for each location and each locus. $F_{I S}$ was estimated according to Weir-Cockerham and was tested using the Markov chain method with 5000 iterations $\left({ }^{*} \mathrm{p}<0.05,{ }^{* *} \mathrm{p}<0.01,{ }^{* * *} \mathrm{p}<0.001\right)$. Bold print indicates $F_{\text {IS }}$ values that remained significant after sequential Bonferroni correction

\begin{tabular}{|c|c|c|c|c|c|c|c|c|}
\hline Sample & Parameter & Gmo02 & MpouBW13 & Pop14c & $\begin{array}{r}- \text { Locus } \\
\text { Pop18a }\end{array}$ & Tch8 & Tch10 & Tch20 \\
\hline $\mathrm{Cb}$ & $\begin{array}{l}N_{\mathrm{A}} \\
H_{\text {obs }} \\
H_{\text {exp }} \\
F_{\mathrm{IS}}\end{array}$ & $\begin{array}{c}29 \\
0.756 \\
0.967 \\
\boldsymbol{+ 0 . 2 2 1}^{* * *}\end{array}$ & $\begin{array}{r}7 \\
0.714 \\
0.724 \\
+0.014\end{array}$ & $\begin{array}{c}7 \\
0.548 \\
0.598 \\
+0.086\end{array}$ & $\begin{array}{c}13 \\
0.568 \\
0.577 \\
+0.016\end{array}$ & $\begin{array}{c}38 \\
0.878 \\
0.974 \\
+0.100^{*}\end{array}$ & $\begin{array}{c}7 \\
0.390 \\
0.575 \\
+\mathbf{0 . 3 2 4}^{* * *}\end{array}$ & $\begin{array}{c}18 \\
0.884 \\
0.907 \\
+0.026\end{array}$ \\
\hline $\mathrm{Au}$ & $\begin{array}{l}N_{\mathrm{A}} \\
H_{\text {obs }} \\
H_{\text {exp }} \\
F_{\mathrm{IS}}\end{array}$ & $\begin{array}{c}32 \\
0.841 \\
0.965 \\
+0.130^{* *}\end{array}$ & $\begin{array}{c}8 \\
0.809 \\
0.766 \\
-0.057\end{array}$ & $\begin{array}{c}10 \\
0.667 \\
0.690 \\
+0.034\end{array}$ & $\begin{array}{c}11 \\
0.596 \\
0.579 \\
-0.029\end{array}$ & $\begin{array}{c}41 \\
0.894 \\
0.973 \\
+\mathbf{0 . 0 8 3}^{* * *}\end{array}$ & $\begin{array}{c}8 \\
0.636 \\
0.647 \\
+0.017\end{array}$ & $\begin{array}{c}24 \\
0.851 \\
0.912 \\
+0.068\end{array}$ \\
\hline Cs & $\begin{array}{l}N_{\mathrm{A}} \\
H_{\text {obs }} \\
H_{\text {exp }} \\
F_{\mathrm{IS}}\end{array}$ & $\begin{array}{c}34 \\
0.745 \\
0.963 \\
+\mathbf{0 . 2 2 8}^{* * *}\end{array}$ & $\begin{array}{c}7 \\
0.815 \\
0.766 \\
-0.064\end{array}$ & $\begin{array}{c}6 \\
0.691 \\
0.753 \\
+0.083^{*}\end{array}$ & $\begin{array}{c}15 \\
0.589 \\
0.600 \\
+0.019\end{array}$ & $\begin{array}{c}42 \\
0.982 \\
0.972 \\
-0.010\end{array}$ & $\begin{array}{c}9 \\
0.618 \\
0.690 \\
+0.105^{* *}\end{array}$ & $\begin{array}{c}24 \\
0.875 \\
0.943 \\
+0.073^{*}\end{array}$ \\
\hline Ir & $\begin{array}{l}N_{\mathrm{A}} \\
H_{\text {obs }} \\
H_{\text {exp }} \\
F_{\mathrm{IS}}\end{array}$ & $\begin{array}{c}37 \\
0.776 \\
0.968 \\
+\mathbf{0 . 2 0 0}^{\text {*** }}\end{array}$ & $\begin{array}{c}9 \\
0.750 \\
0.776 \\
+0.033\end{array}$ & $\begin{array}{c}9 \\
0.625 \\
0.723 \\
+0.137^{*}\end{array}$ & $\begin{array}{c}14 \\
0.680 \\
0.655 \\
-0.038\end{array}$ & $\begin{array}{c}40 \\
0.939 \\
0.974 \\
+0.037\end{array}$ & $\begin{array}{c}11 \\
0.457 \\
0.664 \\
+\mathbf{0 . 3 1 5}^{\text {*** }}\end{array}$ & $\begin{array}{c}25 \\
0.920 \\
0.941 \\
+0.022\end{array}$ \\
\hline Di & $\begin{array}{l}N_{\mathrm{A}} \\
H_{\text {obs }} \\
H_{\text {exp }} \\
F_{\mathrm{IS}}\end{array}$ & $\begin{array}{c}33 \\
0.659 \\
0.967 \\
\mathbf{+ 0 . 3 2 1}^{\text {*** }}\end{array}$ & $\begin{array}{c}8 \\
0.844 \\
0.802 \\
-0.053\end{array}$ & $\begin{array}{c}9 \\
0.581 \\
0.735 \\
+0.211^{* *}\end{array}$ & $\begin{array}{c}11 \\
0.622 \\
0.657 \\
+0.053\end{array}$ & $\begin{array}{c}38 \\
0.950 \\
0.977 \\
+0.028\end{array}$ & $\begin{array}{c}8 \\
0.459 \\
0.659 \\
+0.306^{*}\end{array}$ & $\begin{array}{c}24 \\
0.889 \\
0.944 \\
+0.059^{*}\end{array}$ \\
\hline Wh & $\begin{array}{l}N_{\mathrm{A}} \\
H_{\text {obs }} \\
H_{\text {exp }} \\
F_{\mathrm{IS}}\end{array}$ & $\begin{array}{c}30 \\
0.762 \\
0.966 \\
+\mathbf{0 . 2 1 3}^{\text {***}}\end{array}$ & $\begin{array}{c}7 \\
0.810 \\
0.703 \\
-0.154\end{array}$ & $\begin{array}{c}11 \\
0.690 \\
0.769 \\
+0.103^{*}\end{array}$ & $\begin{array}{c}13 \\
0.556 \\
0.573 \\
+0.030\end{array}$ & $\begin{array}{c}44 \\
0.933 \\
0.980 \\
+0.048^{* *}\end{array}$ & $\begin{array}{c}11 \\
0.333 \\
0.683 \\
+\mathbf{0 . 5 1 5}^{* * *}\end{array}$ & $\begin{array}{c}24 \\
0.889 \\
0.934 \\
+0.049\end{array}$ \\
\hline $\mathrm{Sb}$ & $\begin{array}{l}N_{\mathrm{A}} \\
H_{\text {obs }} \\
H_{\text {exp }} \\
F_{\mathrm{IS}}\end{array}$ & $\begin{array}{c}36 \\
0.822 \\
0.968 \\
+\mathbf{0 . 1 5 2}^{\text {*** }}\end{array}$ & $\begin{array}{c}7 \\
0.745 \\
0.774 \\
+0.039\end{array}$ & $\begin{array}{c}9 \\
0.622 \\
0.736 \\
+0.156\end{array}$ & $\begin{array}{c}14 \\
0.667 \\
0.612 \\
-0.090\end{array}$ & $\begin{array}{c}32 \\
0.800 \\
0.967 \\
+\mathbf{0 . 1 7 4}^{* * *}\end{array}$ & $\begin{array}{c}8 \\
0.622 \\
0.701 \\
+0.114\end{array}$ & $\begin{array}{r}21 \\
0.875 \\
0.932 \\
+0.062\end{array}$ \\
\hline $\mathrm{Fh}$ & $\begin{array}{l}N_{\mathrm{A}} \\
H_{\text {obs }} \\
H_{\text {exp }} \\
F_{\mathrm{IS}}\end{array}$ & $\begin{array}{c}34 \\
0.826 \\
0.963 \\
+0.144^{* *}\end{array}$ & $\begin{array}{c}6 \\
0.809 \\
0.731 \\
-0.107\end{array}$ & $\begin{array}{c}8 \\
0.522 \\
0.745 \\
+\mathbf{0 . 3 0 2}^{* * *}\end{array}$ & $\begin{array}{c}11 \\
0.438 \\
0.449 \\
+0.026\end{array}$ & $\begin{array}{c}35 \\
0.896 \\
0.966 \\
+0.073^{* *}\end{array}$ & $\begin{array}{c}10 \\
0.362 \\
0.557 \\
+0.353^{* *}\end{array}$ & $\begin{array}{c}22 \\
0.938 \\
0.928 \\
-0.011\end{array}$ \\
\hline $\mathrm{Db}$ & $\begin{array}{l}N_{\mathrm{A}} \\
H_{\text {obs }} \\
H_{\text {exp }} \\
F_{\mathrm{IS}}\end{array}$ & $\begin{array}{c}34 \\
0.795 \\
0.969 \\
\mathbf{+ 0 . 1 8 1}^{* * *}\end{array}$ & $\begin{array}{r}7 \\
0.818 \\
0.769 \\
-0.065\end{array}$ & $\begin{array}{c}9 \\
0.581 \\
0.777 \\
+0.254^{* *}\end{array}$ & $\begin{array}{c}16 \\
0.711 \\
0.726 \\
+0.021\end{array}$ & $\begin{array}{c}38 \\
0.977 \\
0.973 \\
-0.004\end{array}$ & $\begin{array}{c}7 \\
0.488 \\
0.696 \\
+\mathbf{0 . 3 0 2}^{* * *}\end{array}$ & $\begin{array}{c}22 \\
0.911 \\
0.937 \\
+0.028\end{array}$ \\
\hline Sk & $\begin{array}{l}N_{\mathrm{A}} \\
H_{\text {obs }} \\
H_{\text {exp }} \\
F_{\mathrm{IS}}\end{array}$ & $\begin{array}{c}31 \\
0.841 \\
0.966 \\
\mathbf{+ 0 . 1 3 1}^{* * *}\end{array}$ & $\begin{array}{c}8 \\
0.696 \\
0.764 \\
+0.090\end{array}$ & $\begin{array}{c}9 \\
0.630 \\
0.703 \\
+0.105\end{array}$ & $\begin{array}{c}13 \\
0.674 \\
0.718 \\
+0.062\end{array}$ & $\begin{array}{c}33 \\
0.889 \\
0.969 \\
+0.083^{* *}\end{array}$ & $\begin{array}{c}8 \\
0.488 \\
0.665 \\
+\mathbf{0 . 2 6 8}^{* * *}\end{array}$ & $\begin{array}{c}20 \\
0.891 \\
0.940 \\
+0.052\end{array}$ \\
\hline & Total $N_{\mathrm{A}}$ & $\begin{array}{c}52 \\
782\end{array}$ & 11 & 18 & 24 & 63 & 15 & 39 \\
\hline & $\begin{array}{l}\text { Mean } H_{\text {obs }} \\
\text { Mean } H_{\text {exp }}\end{array}$ & $\begin{array}{l}0.782 \\
0.966\end{array}$ & $\begin{array}{l}0.781 \\
0.757\end{array}$ & $\begin{array}{l}0.616 \\
0.723\end{array}$ & $\begin{array}{l}0.610 \\
0.615\end{array}$ & $\begin{array}{l}0.914 \\
0.972\end{array}$ & $\begin{array}{l}0.485 \\
0.654\end{array}$ & $\begin{array}{l}0.892 \\
0.932\end{array}$ \\
\hline
\end{tabular}


related to their proximity within hydrological features than to direct geographic distance, in that currents may link distant local populations, while hydrological fronts may separate close neighbours.

\section{RESULTS}

\section{Genetic diversity and heterozygote deficiencies}

The level of variability of the microsatellites of whiting Merlangius merlangus surveyed in the present study appeared relatively heterogeneous, with the total number of alleles varying between 11 (MpouBW13) and 63 (Tch8) and mean observed heterozygosity between 0.610 (Pop18a) and 0.914 (Tch8) (Table 3). For each locus, the genetic diversity observed within samples was of the same magnitude over the whole data set.

Of the 7 microsatellites screened, 4 (Gmo02, Pop14c, Tch8 and Tch10) exhibited substantial departures from Hardy-Weinberg equilibrium (Table 3). In particular, strong and significant heterozygote deficiencies were observed (even after sequential Bonferroni correction) for Gmo02 and Tch10 in the majority of the samples (except Au for Tch10).

\section{Genetic structure}

Weir \& Cockerham's $\theta(\theta=0.0013)$ showed weak global multi-locus genetic differentiation over the entire data set, while the global multi-locus exact test of genic differentiation found a highly significant genetic structure $(p=0.0001)$ (Table 4). Among the 7 loci considered individually, only Pop18a displayed a significant global $\theta$-value $(\theta=0.0052, p<0.05)$. In addition, Gmo02 ( $p=0.0058)$, MpouBW13 ( $p=0.0278)$ and Tch8 $(p=0.0116)$ showed significant exact tests of global genic differentiation. Finally, only the exact test calculated for Gmo02 remained significant when a sequential Bonferroni correction was performed.

Pairwise Weir \& Cockerham's $\theta$ underlined some significant genetic structure between the Bay of Biscay $(\mathrm{Cb} \& \mathrm{Au})$ and some samples stemming from the North Sea (Fh \& Db) (Table 5). Likewise, pairwise exact tests of genic differentiation clearly showed a significant differentiation of the southern Bay of Biscay sample $(\mathrm{Cb})$ from all other samples, with the exception of $\mathrm{Au}$, stemming from the northern Bay of Biscay (Table 5). Au appeared significantly distinct from 2 samples from the North Sea (Sb \& Db).

Limited genetic structure was detected between western and eastern waters around the British Isles,

Table 4. Merlangius merlangus. Single- and multi-locus global assessment of genetic differentiation between samples using: (1) $F_{\mathrm{ST}}$ estimated with Weir \& Cockerham's $\theta$ and tested using 10000 permutations $\left({ }^{*} \mathrm{p}<0.05\right)$ and $(2)$ exact tests of genic differentiation tested with the Markov chain method using 5000 iterations (bold print indicates significant p-values). Only the exact test of genic differentiation calculated for Gmo02 remained significant after sequential Bonferroni correction (underlined)

\begin{tabular}{|lcccccccc|}
\hline & Gmo02 & MpouBW13 & Pop14c & Pop18a & Tch8 & Tch10 & Tch20 & All loci \\
\hline$\theta$ & 0.0001 & 0.0024 & 0.0001 & $0.0052^{*}$ & 0.0009 & 0.0001 & 0.0015 & 0.0013 \\
Exact test & $\underline{\mathbf{0 . 0 0 5 8}}$ & $\mathbf{0 . 0 2 7 8}$ & 0.3608 & 0.1070 & $\mathbf{0 . 0 1 1 6}$ & 0.0826 & 0.0876 & $\mathbf{0 . 0 0 0 1}$ \\
\hline
\end{tabular}

Table 5. Merlangius merlangus. Estimation of $F_{\mathrm{ST}}(\theta)$ (above diagonal) and exact tests of genic differentiation (below diagonal) for each pair of locations. Pairwise $\theta$-values were calculated according to Weir \& Cockerham and were tested using 10000 permutations ( $\left.{ }^{*} \mathrm{p}<0.05\right)$. Pairwise exact tests were tested using the Markov chain method with 5000 iterations (bold print indicates significant p-values). Only the exact test of genic differentiation calculated between $\mathrm{Fh}$ and $\mathrm{Cb}$ samples remained significant after sequential Bonferroni correction (underlined)

\begin{tabular}{|lccccccccccc}
\hline & $\mathrm{Cb}$ & $\mathrm{Au}$ & $\mathrm{Cs}$ & $\mathrm{Ir}$ & $\mathrm{Di}$ & $\mathrm{Wh}$ & $\mathrm{Sb}$ & $\mathrm{Fh}$ & $\mathrm{Db}$ & $\mathrm{Sk}$ \\
\hline $\mathrm{Cb}$ & - & -0.0012 & 0.0041 & 0.0030 & 0.0021 & 0.0029 & 0.0021 & $0.0055^{*}$ & \multicolumn{2}{c}{$0.0102^{* *}$} & 0.0036 \\
$\mathrm{Au}$ & 0.2519 & - & 0.0013 & 0.0029 & -0.0006 & -0.0004 & 0.0006 & 0.0022 & $0.0075^{*}$ & 0.0008 \\
$\mathrm{Cs}$ & $\mathbf{0 . 0 0 1 9}$ & 0.1640 & - & -0.0007 & -0.0027 & -0.0007 & -0.0026 & 0.0027 & -0.0003 & -0.0001 \\
$\mathrm{Ir}$ & $\mathbf{0 . 0 0 7 4}$ & 0.0974 & 0.1628 & - & -0.0009 & -0.0002 & -0.0007 & $0.0068^{*}$ & 0.0006 & -0.0005 \\
$\mathrm{Di}$ & $\mathbf{0 . 0 1 9 8}$ & 0.3177 & 0.1957 & 0.2154 & - & -0.0002 & -0.0035 & $0.0052^{*}$ & -0.0023 & -0.0015 \\
$\mathrm{Wh}$ & $\mathbf{0 . 0 4 3 4}$ & 0.4984 & 0.1384 & 0.1601 & 0.3750 & - & -0.0025 & -0.0013 & 0.0027 & -0.0004 \\
$\mathrm{Sb}$ & $\mathbf{0 . 0 3 6 8}$ & $\mathbf{0 . 0 0 7 0}$ & 0.2509 & 0.0583 & 0.4782 & 0.3024 & - & 0.0027 & 0.0021 & 0.0008 \\
$\mathrm{Fh}$ & $\mathbf{0 . 0 0 0 4}$ & 0.1804 & 0.0941 & $\mathbf{0 . 0 0 6 5}$ & $\mathbf{0 . 0 1 3 8}$ & 0.2088 & $\mathbf{0 . 0 0 3 6}$ & - & $0.0100^{* *}$ & $0.0066^{*}$ \\
$\mathrm{Db}$ & $\mathbf{0 . 0 0 1 3}$ & $\mathbf{0 . 0 3 4 3}$ & 0.3423 & 0.3290 & 0.5519 & 0.2837 & $\mathbf{0 . 0 1 3 6}$ & $\mathbf{0 . 0 0 7 4}$ & - & -0.0012 \\
$\mathrm{Sk}$ & $\mathbf{0 . 0 0 2 7}$ & 0.1815 & 0.2757 & 0.2030 & 0.2159 & 0.2850 & $\mathbf{0 . 0 1 0 6}$ & $\mathbf{0 . 0 0 1 2}$ & 0.5290 & - \\
\hline
\end{tabular}




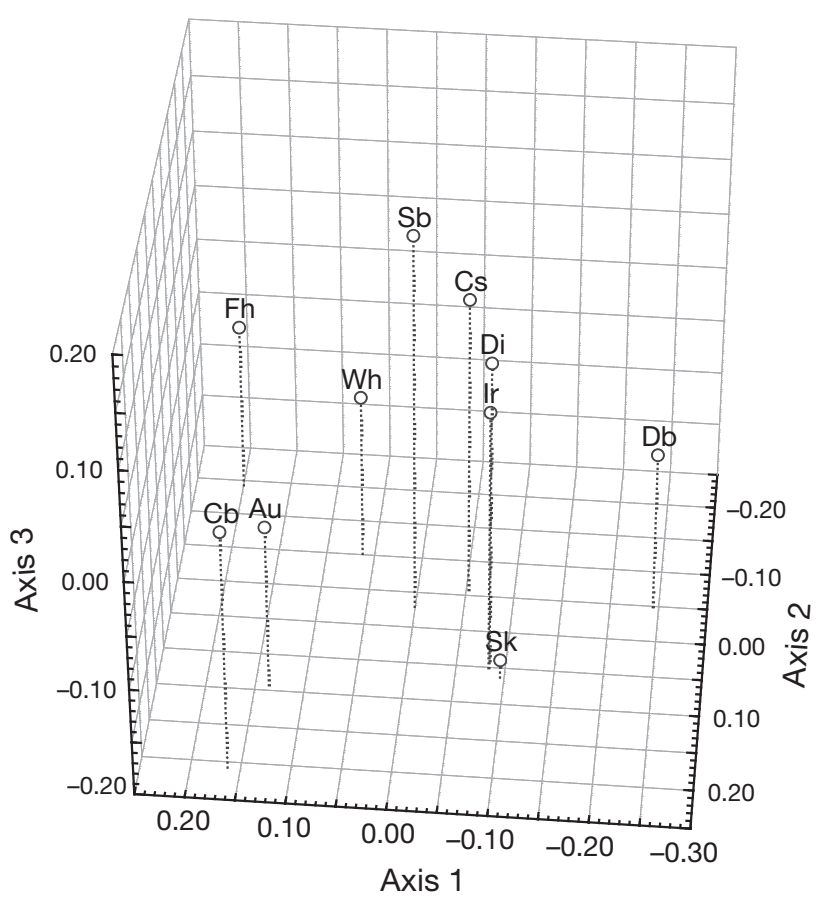

Fig. 2. Merlangius merlangus. Arrangement of the samples on the 3 first axes of the principal component analysis

since only the pairs Fh \& Di and Fh \& Ir displayed significant $\theta$-values and significant exact tests of genic differentiation. Furthermore, a lack of genetic differentiation was observed among samples off the western UK mainland, from the Celtic Sea to the western Hebrides. In contrast, pairwise $\theta$-values underlined some significant genetic structure within the North Sea, between Fh \& Db $(\theta=0.0100, \mathrm{p}<0.01)$ and between Fh \& Sk $(\theta=0.0066, p<0.05)$. Interestingly, the level of differentiation was of the same magnitude between the Bay of Biscay and North Sea samples and within the North Sea $(\theta \sim 0.005$ to 0.010$)$. This genetic structure was further supported by exact tests of genic differentiation, since the 4 North Sea samples $(\mathrm{Sb}, \mathrm{Fh}$, $\mathrm{Db} \& \mathrm{Sk}$ ) appeared to be significantly differentiated from each other, with the exception of the comparison between $\mathrm{Db} \&$ Sk.

Both $\theta$-values and exact tests became non-significant after sequential Bonferroni correction, with the exception of the exact test of genic differentiation between $\mathrm{Cb} \& \mathrm{Fh}$. However, the Bonferroni method is considered highly conservative and thus unsuitable when $>5$ comparisons are considered (Altman 1991). As a consequence, results that were non-significant after Bonferroni correction were not rejected, but only considered cautiously, as suggested by Hutchinson et al. (2001).

The PCA revealed some genetic structure among samples, congruently with $\theta$-values and exact tests of genetic differentiation (Fig. 2). The 3 first axes of the PCA explained $25.17,16.46$ and $11.79 \%$ of the total variance, respectively, representing a large proportion of the genetic variance over the entire data set. The PCA allowed discrimination of samples from the Bay of Biscay $(\mathrm{Cb} \& \mathrm{Au})$ compared with the others around the British Isles. Furthermore, samples west of the British Isles appeared relatively close to each other (Cs, Ir, Di and, to a lower extent, Wh), while those stemming from the North Sea showed some evidence of genetic heterogeneity ( $\mathrm{Sb}, \mathrm{Fh}, \mathrm{Db} \& \mathrm{Sk})$.

Finally, the Mantel test highlighted a lack of correlation between geographical distances and linearised $\theta$ $(Z=193.42$, ns), suggesting a lack of isolation by distance in whiting throughout European waters.

\section{DISCUSSION}

\section{Heterozygote deficiencies: a common problem in microsatellites}

Among the 7 loci genotyped in whiting Merlangius merlangus during this study, Gmo02 and Tch10 displayed highly significant heterozygote deficiencies, and, at a lower level, Pop14c and Tch8 showed substantial deficiencies. Such departures are commonly observed in microsatellite surveys and appeared to be particularly prominent in the previous study conducted on whiting (Rico et al. 1997). Several hypotheses may explain these heterozygote deficiencies, including: (1) selection, (2) inbreeding, (3) Wahlund effect (e.g. a mixture of individuals from differentiated populations in the same sample), (4) homoplasy, or (5) technical artefacts such as null or mis-scoring alleles.

(1) Microsatellites are considered to be selectively neutral (Estoup et al. 1998), and thus, selection appears to be an unlikely explanation. However, selection processes operating on particular loci may be reflected on closely linked microsatellites through hitch-hiking phenomenon, thus inducing departures from HardyWeinberg expectations. (2) Inbreeding depression appears unrealistic in whiting, since marine species are commonly characterised by large population sizes. (3) A Wahlund effect seems inappropriate to explain heterozygote deficiencies in the present data set, since these deviations are more linked to particular loci rather than to particular samples. This hypothesis is reinforced by the fact that both loci displaying the highest global $\theta$-values (MpouBW13 \& Pop18a) did not show any significant departures from Hardy-Weinberg equilibrium. In addition, the mixture in the same sample of individuals stemming from highly differentiated population units seems improbable regarding the low pairwise $\theta$-values observed in this study, particularly 
for samples west of mainland UK that did not appear genetically differentiated; eventually, the occurrence in the same sample of individuals stemming from genetically differentiated populations could be more probable for samples collected within the North Sea, where significant genetic structure was observed. (4) Homoplasy may be a more likely hypothesis, especially for the most variable loci, Tch8 and Gmo02. When microsatellites are submitted to particularly high mutation rates, alleles of the same size may not be identical by descent and would thus induce heterozygote deficiencies. (5) Finally, the presence of null alleles or allele scoring errors may be highly probable at microsatellite loci (see Rico et al. 1997). Null alleles are often observed due to non-amplifications induced by mutation(s) in at least one of the priming sites, and such PCR artefacts seem particularly probable when non-species-specific loci are used, as in the present study. Moreover, allele mis-scoring due to shadow or stutter bands constitutes a common problem in microsatellite surveys, stutter bands probably being due to slipped strand mispairing during PCR (see references in Rico et al. 1997).

To conclude, although a Wahlund effect cannot be completely rejected as an explanation for the heterozygote deficiencies in the North Sea samples, technical artefacts such as null alleles appear more probable for the majority of the deficiencies observed in the data set, given the use of non-species-specific primers. Furthermore, homoplasy is also a possibility in the most variable loci, Gmo02 and Tch8.

\section{Weak population structure in Atlantic waters}

The low level of genetic differentiation underlined between whiting samples in the northeast Atlantic and adjacent waters is of the same magnitude as previously observed in gadid fish in the same geographical area, such as cod Gadus morhua (Hutchinson et al. 2001), hake Merluccius merluccius (Lundy et al. 1999) and blue whiting Micromesistius poutassou (Ryan et al. 2005). The weak genetic structure generally displayed by marine organisms may be explained mainly by the considerable gene flow in the highly dispersive marine environment and the characteristically large population sizes. This high potential for gene flow is well illustrated in the present study by the lack of differentiation to the west of the UK mainland: the genetic homogeneity found from the Celtic Sea to the western Hebrides may result, at least in part, from the widespread dispersal of the young pelagic stages through passive drift with the current systems. For example, passive dispersal may be ensured from Porcupine Bank to northern Scotland by the general north-north- easterly drift of the North Atlantic Current and possible advection by the Shelf Edge Current (Pingree \& Le Cann 1989), as demonstrated for blue whiting and mackerel Scomber scombrus (Bartsch \& Coombs 1997 , 2004).

Furthermore, samples to the west of the British Isles did not appear to be differentiated from North Sea samples (with the exception of the Irish Sea and Flamborough Head samples). First, the branching of the North Atlantic Current into the North Sea along the Norwegian coast (Turell 1992) may allow a high connectivity between the north east Atlantic and the northern North Sea through passive dispersal of the young pelagic stages along this route. Moreover, substantial gene flow through passive drift between the southwestern British Isles and the southern North Sea could be ensured by the residual current flowing eastwards from the Atlantic to the Southern Bight through the English Channel (Prandle et al. 1996). However, Atlantic and Celtic shelf waters are, to some extent, seasonally isolated from the English Channel by the Ushant front (from the Brittany peninsular across the western English Channel to the UK coast) that appears with the increase of temperatures in spring and lasts until the mixing of the water column in autumn. Therefore, it may be hypothesised that the long pelagic phase and the extended spawning period of whiting could mitigate, to some extent, the influence of such temporary oceanographic barriers to the passive dispersal of larvae and young pelagic stages.

Alternatively, the limited differentiation observed between eastern and western waters around the British Isles, and particularly to the west of the British Isles, may be due to the recent origin of populations, which would imply a weak genetic structure undetectable with the markers used in the present study. However, this possibility appears unrealistic given the substantial level of genetic structure demonstrated for whiting within the North Sea that originated with the raising of the sea level after the Last Glacial Maximum only 15000 yr ago (Andersen \& Borns 1994).

Although the highly dispersive environment of Atlantic waters is thought to prevent genetic differentiation in whiting along the western coasts of the British Isles, whiting from the Bay of Biscay and especially those from the most southerly sampling site (Cape Breton) appeared genetically differentiated from more northern samples. This can be attributed, in part, to the separation west of the British Isles of the North Atlantic Current into the main northwesterly flow and a relatively weak southern offshoot as an anti-cyclonic gyre of surface waters in Biscay (Pingree 1993). A southerly flow towards Biscay is supported in the model results for the planktonic stages of mackerel and blue whiting (Bartsch \& Coombs 1997, 2004), 
although residual flow on the shelf of eastern Biscay may remain mainly to the northwest, but diminishs to weak levels by the area of the Celtic shelf (Pingree \& Le Cann 1989). The potential for some element of southerly flow and weak transport on the Celtic shelf would then provide for divergent distribution routes in the near-surface waters in which the planktonic stages of whiting are located (Conway et al. 1997). A contrasting situation is observed for hake Merluccius merluccius, which showed a lack of differentiation in populations from Cape Breton to the Celtic Sea (Lundy et al. 1999). This can be related to hake spawning at the shelf edge, with the eggs and larval stages occurring at depths of up to several hundred metres (Motos et al. 2004), hence being directly influenced by the northwesterly flowing Shelf Edge Current linking Biscay with areas to the west of the British Isles. Moreover, hake juveniles are relatively widespread at depths close to $150 \mathrm{~m}$, while nurseries of whiting are localised in more coastal areas around 5 to $30 \mathrm{~m}$ depth (Quéro \& Vayne 1997). Thus, hake may be more susceptible to wide dispersion at the juvenile stages, whereas the close linkage of whiting juveniles to coastal waters would favour population structuring.

\section{Complex genetic structure patterns in the North Sea}

Child (1988), using allozyme markers, observed a lack of genetic structure within the North Sea in 4 gadoids (whiting, cod Gadus morhua, haddock Melanogrammus aeglefinus and saithe Pollachius virens), and thus hypothesised that wind-driven currents may allow sufficient mixing during the larval phase to prevent genetic differentiation and maintain panmixia in fish species in this basin. In contrast, substantial genetic differentiation was observed with microsatellite loci in cod within the North Sea (Hutchinson et al. 2001), thus suggesting that the homogeneity showed by allozymes may be due to balanced selection, as previously suggested for cod in the northwest Atlantic (Pogson et al. 1995). The present study showed a significant level of genetic structuring of whiting within the North Sea, and identified at least 3 distinct population units in this area: Southern Bight, Flamborough Head and a third unit grouping the Dogger Bank and the southern Norwegian coast (Skarvöyni). Interestingly, this genetic structure observed in whiting is relatively similar to that observed in cod (Hutchinson et al. 2001). Marine species can exhibit strong genetic structure, when hydrographic features (e.g. oceanic fronts, gyres) associated with particular ecological traits of species (e.g. homing behaviour) produce restricted gene flow between discrete spawning units. Such a synergistic impact of hydrographic and behav- ioural factors on the genetic structure of marine fish has previously been reported in cod (Ruzzante et al. 2000) and Atlantic herring Clupea harengus (McPherson et al. 2004).

Considerable evidence has been reported, on the basis of gall-bladder parasites, tag-recapture data, or meristic counts (Gamble 1959, Williams \& Prime 1966, Kabata 1967, Hislop \& MacKenzie 1976, Pilcher et al. 1989), that 2 distinct whiting populations are distributed one to the north and the other to the south of the Dogger Bank. The present results obtained with microsatellites are consistent with a differentiation between whiting stemming from northern (Skarvöyni and Dogger Bank) and southern (Southern Bight) parts of the North Sea. The Dogger Bank has been suggested to act as a physical barrier that prevents mixing between southern and northern populations (Pilcher et al. 1989). Moreover, segregation of these 2 population units could be associated with the Flamborough front separating mixed water of the southern North Sea from seasonally stratified waters of the central and northern North Sea. Passive dispersal in the central and northern North Sea may be limited also by cyclonic patterns of water circulation in this area (Brown et al. 1999), thus preventing mixing between the 2 populations at the larval and juvenile pelagic stages. This isolation during early developmental stages, between the southern and northern North Sea, is well supported by the differences observed in the number of vertebrae in whiting from north and south of the Dogger Bank (Gamble 1959). Indeed, mersitic characters are influenced by environmental factors and are fixed during early-life development (Lindsey 1975). Consequently, differences in these phenotypical traits tend to indicate isolation of individuals in distinct physical environments during their early life stages, thus suggesting the existence of discrete larval retention systems associated with particular hydrographic features.

Furthermore, the present study provided evidence of a more complex population structure than previously suggested in whiting, with the identification of an additional discrete population located in the area of Flamborough Head. The segregation of the Flamborough Head sample may be associated with its location within the frontal zone separating seasonally northern and southern waters of the North Sea. Interpretation of the genetic groupings in relation to current systems and potential dispersal routes is hindered by the complex oceanography of the North Sea and the limited number of sampling sites in the present study. Potential isolation of all sampling sites is feasible because none are linked by direct surface currents or transport routes (see Lee 1980). Grouping of the Dogger and Norwegian samples appears unlikely from an oceanographic perspective because of the sharp separation of 
central North Sea waters from Norwegian coastal waters by the currents of the water exchange between the Baltic and North Sea.

\section{'Member/vagrant' and 'adopted migrant' hypotheses}

Oceanographic retention systems of pelagic stages may not be sufficient by themselves to maintain genetic differentiation in limited areas of the North Sea. For this, it appears essential that adults repeatedly return to spawn with relatively high fidelity to their natal spawning area. Such homing behaviour may be either natal (Iles \& Sinclair 1982) or learned (McQuinn 1997). Natal homing is assumed to involve endogenous processes, such as an internal sense of direction, sensitivity to pheromonal molecules, or imprinting processes (see references in McQuinn 1997). Such behaviour is central to the discrete population concept (e.g. 'member/vagrant' hypothesis) that considers larval retention mechanisms and natal homing as key factors to ensure life-cycle closure and temporal persistence of discrete populations (Iles \& Sinclair 1982). Alternatively, a learned homing behaviour implies a social transmission of migration routes from older, experienced fish to young recruits. This behaviour is central to the metapopulation concept (e.g. 'adopted migrant' hypothesis) described by McQuinn (1997). Considering this model, juveniles do not necessarily recruit to their natal population, but may be adopted by a neighbouring population. Therefore, the extent of temporal stability of the physical or behavioural isolating systems limiting juvenile dispersal to neighbouring populations determines the degree of genetic exchange among them. Inter-annual variability in the strength of these isolating mechanisms would result in variable inter-annual mixing between local populations. Of course, neighbouring populations are defined in an ecological sense, since 2 local populations can be geographical neighbours, but have limited exchange because their migration routes do not overlap in time and space or they inhabit separate oceanographic systems, as appears to be the case for whiting in the North Sea. This pattern of juvenile dispersal has previously been demonstrated in herring Clupea harengus by McQuinn (1997), who argued that a social transmission mechanism for passing on habitat information between generations is more advantageous than natal homing in variable marine environments. Indeed, in such an unstable and unpredictable environment, learned homing allows rapid colonisation of new habitats or recolonisation after collapse, thus increasing species resilience.

Parasitic infestation studies and tag-recapture data (Williams \& Prime 1966, Kabata 1967, Hislop \& Mac-
Kenzie 1976, Pilcher et al. 1989) have suggested limited mixing during adult demersal life between populations of whiting within the North Sea and along the western margin of the British Isles. In parallel, the present study underlined a significant genetic structure for this species in the North Sea, while a lack of genetic differentiation was shown to the west of the UK mainland; these contrasting results are associated with the possible influence of hydrographic factors on the passive dispersal of young pelagic stages. This suggests that gene flow may be ensured essentially during the larval pelagic phase and that adults may acquire a substantial degree of fidelity to the spawning unit they have adopted. Thus, natal homing appears unrealistic in whiting and the 'adopted migrant' hypothesis seems more probable. When hydrographic factors prevent larval dispersal to neighbouring populations, young fish would most likely recruit to their natal population and adopt the behaviour patterns of that population. In more dispersive environments, such as that to the west of the British Isles, the passive dispersion of young stages may be substantial; thus, a significant number of juveniles would likely recruit to neighbouring populations.

\section{Perspectives for future management}

Despite results obtained over $>40 \mathrm{yr}$, the North Sea is currently considered as a single stock for management of the whiting fishery (ICES 2004). Considering the findings of the present study based on genetic tools, it appears that the North Sea is composed of several population units, while the western British Isles encompasses a single metapopulation. Further genetic investigations, using a more extensive sampling design in the North Sea, would be beneficial in providing more definitive knowledge of the population structure of whiting, since it is recognised that the present study is based on data from only a limited number of sites. In addition, the inter-annual stability of the genetic differentiation patterns observed in this study should be tested. Indeed, population genetics could become a useful tool for fisheries management, but only if temporally stable patterns of genetic structure can be established (Lundy et al. 1999, McPherson et al. 2004). Furthermore, more effort should be allocated to sampling in Atlantic waters, to obtain a more detailed description of whiting population structure. Notably, it would be interesting to increase the sample size to 50-100 individuals and/or to add new loci in order to enhance the ability to detect weak genetic differentiation between whiting populations. Additionally, defining the reproductive status of individuals (e.g. through gonadal maturation staging) would probably improve 
the identification of spawning units and further the investigation of the homing behaviour hypotheses in whiting. Moreover, performing phenotypical traits studies (parasitic infestation, otolith microchemistry, meristic counts) simultaneously with genetic analyses could be useful in determining the origin and life history of spawning individuals collected on each spawning ground.

An accurate definition of population boundaries constitutes the basis for ensuring the viability of exploited marine resources through coherent management plans. A failure to identify population structure could lead to over-fishing of some stock components and ultimately to the erosion of genetic diversity at the species level through local population depletions or extinctions. For example, genetic erosion due to over-fishing has been demonstrated for the original cod Gadus morhua population at Flamborough Head (Hutchinson et al. 2003). The maintenance of intra-specific genetic diversity is particularly crucial to conserving the resilience capacities of exploited stocks and the evolutionary potential of species to adapt to environmental change.

Finally, the whiting population of the Bay of Biscay, and particularly from the southern part of the bay, should be further investigated to obtain a more complete assessment of its status. The southern Bay of Biscay is strongly affected by global warming, with an increase of surface water temperature of $\sim 1.5^{\circ} \mathrm{C}$ over the period 1972 to 1993 (Koutsikopoulos et al. 1998). Water temperature is known to influence survival of fish (Wegner et al. 2003), and, thus, the southern Bay of Biscay, representing the southern limit of the distribution of whiting, could be a particularly relevant site to explore the possibility of local adaptation to thermal stress.

Acknowledgements. We are grateful to M. Armstrong, R. Bellail, J. Ellis, V. Howden, A. Lyons, G. Morandeau, M. O'Sullivan, B, Robert, G. Stéphan, J. Trivillic and Y. Verrin for helping us to collect the samples used in this study. We thank N. Gloaguen and L. Quiniou for assistance and technical help. Furthermore, we are grateful to the anonymous reviewers for their helpful comments and suggestions to improve the manuscript. This research was supported by the Région Bretagne.

\section{LITERATURE CITED}

Altman DG (1991) Practical statistics for medical research. Chapman \& Hall, London

Andersen BG, Borns HW Jr (1994) The Ice Age world. Scandinavian University Press, Oslo

Bartsch J, Coombs S (1997) A numerical model of the dispersion of blue whiting larvae, Micromesistius potassiou (Risso) in the eastern North Atlantic. Fish Oceanogr 6: 141-154

Bartsch J, Coombs SH (2004) An individual-based model of the early life history of mackerel (Scomber scombrus) in the eastern North Atlantic, simulating transport, growth and mortality. Fish Oceanogr 6:365-379

Belkhir K, Borsa P, Chikhi L, Raufaste N, Bonhomme F (1996) GENETIX v.4.05 logiciel sous Windows TM pour la génétique des populations. Laboratoire Génome, Populations, Interactions CNRS UMR 5000, University of Montpellier II

Brooker AL, Cook D, Bentzen P, Wright JM, Doyle RW (1994) Organization of microsatellites differs between mammals and cold-water teleost fishes. Can J Fish Aquat Sci 51: 1959-1966

Brown J, Hill AE, Fernand L, Horsburgh KJ (1999) Observation of a seasonal jet-like circulation at the central North Sea cold pool margin. Estuar Coast Shelf Sci 48:343-355

Carr SM, Snellen AJ, Howse KA, Wroblewski JS (1995) Mitochondrial DNA sequence variation and genetic stock structure of Atlantic cod (Gadus morhua) from bay and offshore locations on the Newfoundland continental shelf. Mol Ecol 4:79-88

Child AR (1988) Population genetics of cod (Gadus morhua (L.)), haddock (Melanogrammus aeglefinus (L.)), whiting (Merlangius merlangus (L.)) and saithe (Pollachius virens (L.)). MAFF Fish Res Technol Rep 87:1-27

Conway DVP, Coombs SH, Smith C (1997) Vertical distribution of fish eggs and larvae in the Irish Sea. ICES J Mar Sci 54:136-147

Estoup A, Rousset F, Michalakis Y, Cornuet JM, Adriamanga M, Guyomard R (1998) Comparative analysis of microsatellite and allozyme markers: a case study investigating microgeographic differentiation in brown trout (Salmo trutta). Mol Ecol 7:339-353

Galvin P, McGregor D, Cross T (1995) A single locus PCR amplified minisatellite region as a hypervariable genetic marker in gadoid species. Aquaculture 137:31-40

Gamble R (1959) Investigations of the sub-division of North Sea whiting populations, Part I. Further observations on the vertebral counts of whiting in the North Sea area. ICES Comm Meet [Near Northern Seas Committee] /36

Goudet J (1999) PCA-GEN for Windows V. 1.2. Institute of Ecology, University of Lausanne

Hislop JRG, MacKenzie K (1976) Population studies of the whiting Merlangius merlangus (L.) of the northern North Sea. J Cons Int Explor Mer 37:98-111

Hutchinson WF, Carvalho GR, Rogers SI (2001) Marked genetic structuring in localised spawning populations of cod (Gadus morhua) within the North Sea and adjoining waters as revealed by microsatellites. Mar Ecol Prog Ser 223:251-260

Hutchinson WF, Van Oosterhout C, Rogers SI, Carvalho GR (2003) Temporal analysis of archived samples indicates marked genetic changes in declining North Sea cod (Gadus morhua). Proc R Soc Lond B 270:2125-2132

ICES (International Council for Exploration of the Sea) (2004) Report of the ICES advisory committee on fishery management and advisory committee on ecosystems. ICES Advice 1, ICES, Copenhagen

Iles TD, Sinclair M (1982) Atlantic herring: stock discreteness and abundance. Science 215:627-633

Kabata Z (1967) Whiting stocks and their gall-bladder parasites in British waters. Mar Res 2:5-11

Koutsikopoulos C, Beillois P, Leroy C, Taillefer F (1998) Temporal trends and spatial structures of the sea surface temperature in the Bay of Biscay. Oceanol Acta 21:335-344

Lage CR, Kornfield I (1999) Isolation and characterization of microsatellite loci in Atlantic haddock (Melanogrammus aeglefinus). Mol Ecol 8:1355-1357

Lee AJ (1980) North Sea: physical oceanography. In: Banner FT, Collins MB, Massie KS (eds) The north-west European 
shelf seas: the sea bed and the sea in motion. II. Physical and chemical oceanography and physical resources. Elsevier Oceanography Series, Elsevier, Amsterdam

Lindsey CC (1975) Pleomerism, the widespread tendency among related fish species for vertebral number to be correlated with maximum body length. J Fish Res Board Can 32:2453-2469

Lundy CJ, Moran P, Rico C, Milner RS, Hewitt GM (1999) Macrogeographical population differentiation in oceanic environments: a case study of European hake (Merluccius merluccius), a commercially important fish. Mol Ecol 8: 1889-1898

McPherson AA, O'Reilly PT, Taggart CT (2004) Genetic differentiation, temporal stability, and the absence of isolation by distance among Atlantic herring populations. Trans Am Fish Soc 133:434-446

McQuinn IH (1997) Metapopulations and the Atlantic herring. Rev Fish Biol Fish 7:297-329

Moran P, Ryan AW, Rico C, Hewitt GM (1999) Four microsatellite loci in the gadoid fish, blue whiting Micromesistius poutassou (Riso, 1826). Anim Genet 30:462-478

Motos L, Cotano U, Coombs SH, Alvarez P, Santos M (2004) Ichthyoplankton assemblages. In: Borja A, Collins M (eds) Oceanography and marine environment of the Basque country. Elsevier, Amsterdam, p 425-454

O'Reilly PT, Canino MF, Bailey KM, Bentzen P (2000) Isolation of twenty low stutter di- and tetranucleotide microsatellites for population analyses of walleye pollock and other gadoids. J Fish Biol 56:1074-1086

Pilcher MW, Whitfield PJ, Riley JD (1989) Seasonal and regional infestation characteristics of three ectoparasites of whiting, Merlangius merlangus L., in the North Sea. J Fish Biol 35:97-110

Pingree R (1993) Flow of surface waters to the west of the British Isles and in the Bay of Biscay. Deep-Sea Res II 40: 369-388

Pingree R, Le Cann B (1989) Celtic and Armorican slope and shelf residual currents. Prog Oceanogr 23:303-338

Editorial responsibility: Otto Kinne (Editor-in-Chief), Oldendorf/Luhe, Germany
Piry S, Bouget G (1999) POP100GENE v1.1.02. INRA. www.ensam.infra.fr/URLB

Pogson GH, Mesa KA, Boutilier RG (1995) Genetic population structure and gene flow in the Atlantic cod Gadus morhua: a comparison of allozyme and nuclear RFLP loci. Genetics 139:375-385

Prandle D, Ballard G, Flatt D, Harrison AJ and 6 others (1996) Combining modeling and monitoring to determine fluxes of water, dissolved and particulate metals through the Dover Strait. Cont Shelf Res 16:237-257

Quéro JC, Vayne JJ (1997) Les poissons de mer des pêches françaises. Delachaux \& Niestlé, Lausanne

Raymond M, Rousset F (1995) GENEPOP (v.1.2): a population genetics software for exact test and ecumenicism. J Hered 86:248-249

Rice WR (1989) Analyzing tables of statistical tests. Evolution 43:223-225

Rico C, Ibrahim KM, Rico I, Hewitt GM (1997) Stock composition in North Atlantic populations of whiting using microsatellite markers. J Fish Biol 51:462-475

Ruzzante DE, Taggart CT, Lang S, Cook D (2000) Mixedstock analysis of Atlantic cod near the Gulf of St. Lawrence based on microsatellite DNA. Ecol Appl 10: 1090-1109

Ryan AW, Matiangeli V, Mork J (2005) Genetic differentiation of blue whiting (Micromesistius poutassou Risso) populations at the extremes of the species range and at the Hebrides-Porcupine Bank spawning grounds. ICES J Mar Sci 62:948-955

Turell WR (1992) New hypotheses concerning the circulation of the northern North Sea and its relation to North Sea fish stock recruitment. ICES J Mar Sci 49:107-123

Wegner G, Damm U, Purps M (2003) Physical influences on the stock dynamics of plaice and sole in the North Sea. Sci Mar 67:219-234

Williams T, Prime J (1966) English whiting tagging experiments in the North Sea. ICES Comm Meet [Gadoid fish committee] G:10

Submitted: November 3, 2005; Accepted: May 22, 2006

Proofs received from author(s): January 2, 2007 